\title{
Cerium isotope constraints on the nature of the Azores plume
}

\author{
PAUL BEGUELIN ${ }^{1}$, ANDREAS STRACKE ${ }^{1}$, FELIX \\ GENSKE $^{1}$, MICHAEL BIZIMIS ${ }^{2}$, CHRISTOPH BEIER ${ }^{3}$ AND \\ MICHAEL WILLIG ${ }^{1}$ \\ ${ }^{1}$ Institut für Mineralogie, Westfälische Wilhelms Universität \\ ${ }^{2}$ University of South Carolina \\ ${ }^{3}$ University of Helsinki \\ Presenting Author: beguelin@uni-muenster.de
}

The Azores Plateau was formed by excess mantle melting, likely driven by upwelling of the low-density, volatile-rich Azores mantle plume [1]. Traditional radiogenic isotope data $(\mathrm{Sr}-\mathrm{Nd}-\mathrm{Hf}-\mathrm{Pb})$ of Azores islands lavas form multiple converging trends in 2D isotope ratio plots, which have been explained as mixing between a common, and thus volumetrically dominant, Azores plume component, and isotopically diverse recycled components [2]. The occurrence of isotopically ultradepleted melt inclusions in some Azores lavas, however, suggests that highly depleted mantle makes up a volumetrically important part of the Azores plume [3], which does not clearly manifest in the $\mathrm{Sr}-\mathrm{Nd}-\mathrm{Hf}-\mathrm{Pb}$ isotope systematics of the lavas.

We address this issue using a novel tracer: radiogenic cerium isotopes. The ${ }^{138} \mathrm{Ce} /{ }^{136} \mathrm{Ce}$ ratio of a mantle source reflects its time-integrated $\mathrm{La} / \mathrm{Ce}$, which quickly approaches near-zero in the restite during melting, while $\mathrm{Sm} / \mathrm{Nd}$ and $\mathrm{Lu} / \mathrm{Hf}$ retain higher, more variable values. Therefore, variably depleted mantle domains will develop low $\mathrm{Ce}$, but variable $\mathrm{Nd}$, Hf radiogenic isotope ratios, resulting in distinct $\mathrm{Ce}-\mathrm{Nd}$ and $\mathrm{Ce}-\mathrm{Hf}$ isotope characteristics [4].

New Ce isotope data (along with existing $\mathrm{Nd}$, Hf isotope data) for 36 lavas covering the whole Azores Plateau show variable $\varepsilon \mathrm{Ce}(-1.2$ to 0.2$)$ at discrete $\varepsilon \mathrm{Nd}$ and $\varepsilon \mathrm{Hf}$ values resulting in several subparallel trends with shallow negative slopes in $\varepsilon \mathrm{Ce}-\varepsilon \mathrm{Nd}$ and $\varepsilon \mathrm{Ce}-\varepsilon \mathrm{Hf}$ plots. Importantly, these trends do not converge towards a common 'Azores plume component'. Rather, these data suggest that melts from a variably depleted Azores plume mantle mix with locally diverse and isotopically enriched components and contribute to the erupted lavas.

The above mixing trends do no show any obvious correlation with island age, location, or other parameters such as crustal thickness [2]. Instead, the observed isotopic variability of Azores lavas is probably caused by melting locally heterogeneous plume sources and variable subsequent homogenization of the diverse melts by mixing in local magma plumbing systems.

[1] French \& Romanowicz (2015), Nature 525, 95-99.

[2] Beier et al. (2012), Lithos 144, 1-11.

[3] Stracke et al. (2019), Nature Geoscience 12(10), 851-855.

[4] Willig et al. (2020), Geochimica et Cosmochimica Acta $272,36-53$. 